\title{
Clinical characteristics and outcomes of COVID-19 long-term nucleic acid positive patients
}

\author{
Xuan Zhu ${ }^{\mathrm{a}, 1}$, Xinxin Zhu ${ }^{\mathrm{a}, 1}$, Min Wang ${ }^{\mathrm{a}}$, Fang Yang ${ }^{\mathrm{a}}$, Zhibing Sun ${ }^{\mathrm{b}}$, Xiaohong Yang ${ }^{\mathrm{c}, *}$ and \\ Yimin Yan $^{\mathrm{a}, \mathrm{b}, *}$ \\ ${ }^{a}$ Medical College of Wuhan University of Science and Technology, Wuhan, Hubei, China \\ ${ }^{\mathrm{b}}$ Department of Internal Medicine, Xiaogan Hospital Affiliated to Wuhan University of Science and \\ Technology, The Central Hospital of Xiaogan, Xiaogan, Hubei, China \\ ${ }^{\mathrm{c}}$ Department of Infectious Diseases, Xiaogan Hospital Affiliated to Wuhan University of Science and \\ Technology, The Central Hospital of Xiaogan, Xiaogan, Hubei, China
}

Received 23 February 2021

Accepted 29 March 2021

\begin{abstract}
.
OBJECTIVE: This study aimed to investigate the clinical characteristics and outcomes of coronavirus disease-19 (COVID-19) long-term nucleic acid positive patients (hereinafter referred to as CLTAPs).

METHODS: Patients were recruited from the Xiaogan Central Hospital between 16 January 2020 and 28 March 2020. Among the 562 cases of patients with laboratory-identified COVID-19 infection by real-time polymerase chain reaction (qtPCR), 19 cases of COVID-19 patients with more than 41 days from the first to the last time of nucleic acid test were selected as the study group, and 76 cases of age- and gender-matched COVID-19 patients were selected as the control group (hereinafter referred to as C-CLTAPs). Demographic characteristics, clinical symptoms, laboratory examination and computed tomography (CT) imaging characteristics were retrospectively analyzed.

RESULTS: On admission, among the 562 cases of patients with COVID-19, there were 398 cases of ordinary COVID-19 patients, 99 cases of severe COVID-19 patients and 99 cases of critical COVID-19 patients. CLTAPs had milder clinical symptoms and longer viral shedding time in comparison to C-CLTAPs. Compared to C-CLTAPs, CLTAPs had a lower infection index at admission. CLTAPs used less oxygen therapy and a higher proportion of hydroxychloroquine treatment in comparison to C-CLTAPs. In comparison to C-CLTAPs, CLTAPs showed slower pulmonary CT progression and faster pulmonary CT absorption.

CONCLUSION: In this study, out of the 562 cases, we found 19 CLTAPs. The clinical differences between CLTAPs and C-CLTAPs were compared and analyzed. We hope that these finding can provide a theoretical basis for the treatment of CLTAPs.
\end{abstract}

Keywords: COVID-19, CT characteristics, clinical features, CLTAPs, coronavirus

\footnotetext{
${ }^{1}$ These authors contributed equally to the work.

${ }^{*}$ Corresponding authors: Xiaohong Yang, Department of Infectious Diseases, Xiaogan Hospital Affiliated to Wuhan University of Science and Technology, No. 6 Plaza Street, Xiaogan, Hubei 432000, China. Tel.: +86 712 2823821; E-mail: y2851336 @163.com. Yimin Yan, Department of Internal Medicine, Xiaogan Hospital Affiliated to Wuhan University of Science and Technology, No.6 Plaza Street, Xiaogan, Hubei 432000, China. Tel.: +86 712 2348633; E-mail: liweimin15@163.com and yanyimin180@163.com.
} 


\section{Introduction}

In December 2019, the 2019 coronavirus disease broke out in Wuhan, Hubei Province, China. The disease caused by the SARS-cov-2 viral infection was named coronavirus disease-19 (COVID-19) by the World Health Organization (WHO) [1-4]. To date, six kinds of coronavirons have been identified to cause human disease [4] and are inducers of respiratory, intestinal, liver, and neurological diseases [5-7]. COVID-19 has quickly spread to all parts of China and many countries around the world as it is highly contagious [8-12]. Studies have confirmed that the pathogen of the COVID-19 outbreak is highly homologous with the SARS virus, and were named SARS-cov-2 by the International Committee of Virology (ICTV) [13]. At present, there are different reports of the SARS-CoV-2 shedding time, indicating the urgent need to study the replication, immunity and infectivity of SARS-CoV-2. Understanding this is crucial for determining the duration of isolation and antiviral treatment. This also indicates that a large number of basic studies on COVID-19 long-term nucleic acid positive patients (CLTAPs) are needed, including studies on the epidemiological and clinical features. At the same time, the CLTAPs with new coronavirus personal, clinical, laboratory, and radiologic characteristics, treatment, and outcome information is of great reference and research value.

In this present study, the aim was to describe the epidemiological, clinical, laboratory and radiological characteristics, treatment, and outcomes of CLTAPs, and to compare the clinical characteristics and outcomes of the control group (C-CLTAPs). We hope that our findings can provide a theoretical basis for the treatment and prevention of CLTAPs.

\section{Methods}

\subsection{Patients}

A total of 562 confirmed COVID-19 cases at the Xiaogan Central Hospital from 16 January 2020 to 28 March 2020 were collected. The diagnostic criteria meet the requirements of the "Diagnosis and treatment of COVID-19 (7th edition)" issued by the Chinese National Health and Health Committee. This study was approved by the ethics committee of Xiaogan Central Hospital (No. XGLY2020-03-28) and conformed to the Declaration of Helsinki.

\subsection{Data collection}

Patients' personal, clinical, laboratory and radiologic characteristics, epidemiological, treatment, and outcome information were obtained through standardized data collection from electronic medical records. Data entry into the computer database was independently completed and double-checked by two researchers.

\subsection{Computed tomography (CT) image collection}

Two experienced physicians were employed to review the films and conducted quantitative accounting according to the distribution, location, size, morphology, edge, density, and pulmonary manifestations of the lesions.

\subsection{Statistical analysis}

Classification variables were expressed as frequency and percentage, continuous variables were ex- 
Table 1

Demographic and clinical characteristics of the 562 cases with COVID-19

\begin{tabular}{|c|c|}
\hline Demographic and clinical characteristics & $\begin{array}{l}\text { All patients } \\
(n=562)\end{array}$ \\
\hline Age (years)-median (IQR) & $52(43-63)$ \\
\hline \multicolumn{2}{|l|}{ Age groups (years)- $n(\%)$} \\
\hline$\leqslant 39$ & $106(18.86)$ \\
\hline $40-49$ & $114(20.28)$ \\
\hline $50-59$ & $158(28.11)$ \\
\hline $60-69$ & $80(14.23)$ \\
\hline$\geqslant 70$ & $104(18.51)$ \\
\hline \multicolumn{2}{|l|}{ Gender- $n(\%)$} \\
\hline Male & $306(54.45)$ \\
\hline Female & $256(45.55)$ \\
\hline \multicolumn{2}{|l|}{ BMI $\left(\mathrm{kg} / \mathrm{m}^{2}\right)(\%)$} \\
\hline $\mathrm{BMI}<18.5$ & $21(3.74)$ \\
\hline $18.5 \leqslant \mathrm{BMI}<24$ & $284(50.53)$ \\
\hline $24 \leqslant \mathrm{BMI}<28$ & $191(33.99)$ \\
\hline $28 \leqslant \mathrm{BMI}<32$ & $52(9.25)$ \\
\hline $\mathrm{BMI} \geqslant 32$ & $8(1.42)$ \\
\hline \multicolumn{2}{|l|}{ Exposure history- $n(\%)$} \\
\hline History of residence in Wuhan & $59(10.50)$ \\
\hline Wuhan tourism history & $126(22.42)$ \\
\hline Contact history with confirmed patients & $137(24.38)$ \\
\hline Denied a clear contact history & $240(42.70)$ \\
\hline \multicolumn{2}{|l|}{ Comorbidities- $n(\%)$} \\
\hline Smoking & $34(6.05)$ \\
\hline Hypertension & $139(24.73)$ \\
\hline Diabetes & $64(11.39)$ \\
\hline Cardiovascular disease & $31(5.52)$ \\
\hline Cerebrovascular disease & $14(2.49)$ \\
\hline Chronic pulmonary disease & $26(4.63)$ \\
\hline Chronic kidney disease & $5(0.89)$ \\
\hline Chronic liver disease & $37(6.58)$ \\
\hline Rheumatic immune disease & $9(1.60)$ \\
\hline Malignancies & $18(3.20)$ \\
\hline \multicolumn{2}{|l|}{ Clinical symptoms- $n(\%)$} \\
\hline Fever & $457(81.32)$ \\
\hline Cough & $368(65.48)$ \\
\hline Expectoration & $142(25.27)$ \\
\hline Dyspnea & $187(33.27)$ \\
\hline Pharyngalgia & $27(4.80)$ \\
\hline Dizziness & $8(1.42)$ \\
\hline Myalgia & $30(5.34)$ \\
\hline Fatigue & $131(23.31)$ \\
\hline Nausea or vomiting & $42(7.47)$ \\
\hline Diarrhea & $24(4.27)$ \\
\hline Temperature $(\geqslant 37.3)(\%)$ & $146(25.98)$ \\
\hline $\mathrm{SpO} 2(\leqslant 93)(\%)$ & $101(17.97)$ \\
\hline $\mathrm{HR}(>100)(\%)$ & $88(15.66)$ \\
\hline $\mathrm{BP}(\mathrm{SBP} \geqslant 140 ; \mathrm{DBP} \geqslant 90)(\%)$ & $107(19.04)$ \\
\hline \multicolumn{2}{|l|}{ Disease stratification- $n(\%)$} \\
\hline Ordinary & 398 \\
\hline Severe & 99 \\
\hline Critically ill & 65 \\
\hline Median time of viral shedding & $26(18-36)$ \\
\hline
\end{tabular}


Table 2

Demographic and clinical characteristics of C-CLTAPs and CLTAPs

\begin{tabular}{|c|c|c|c|c|}
\hline Demographic and clinical characteristics & $\begin{array}{l}\text { All patients } \\
(n=95)\end{array}$ & $\begin{array}{c}\text { C-CLTAPs } \\
(n=76)\end{array}$ & $\begin{array}{l}\text { CLTAPs } \\
(n=19) \\
\end{array}$ & $p$ value \\
\hline \multicolumn{5}{|l|}{ Characteristics } \\
\hline Age (years)-median (IQR) & $57(48-60)$ & $56(48-60)$ & $57(49-59)$ & 0.944 \\
\hline \multicolumn{5}{|l|}{ Gender- $n(\%)$} \\
\hline Male & $75(78.95)$ & $60(78.95)$ & $15(78.95)$ & 1.000 \\
\hline Female & $20(21.05)$ & $16(21.05)$ & $4(21.05)$ & 1.000 \\
\hline \multicolumn{5}{|l|}{ Exposure history- $n(\%)$} \\
\hline History of residence in Wuhan & $10(10.53)$ & $7(9.21)$ & $3(15.79)$ & 0.403 \\
\hline Wuhan tourism history & $17(17.89)$ & $13(17.11)$ & $4(21.05)$ & 0.688 \\
\hline Contact history with confirmed patients & $26(27.37)$ & $20(26.32)$ & $6(31.58)$ & 0.645 \\
\hline Denied a clear contact history & $42(44.21)$ & $36(47.37)$ & $6(31.58)$ & 0.215 \\
\hline \multicolumn{5}{|l|}{ Comorbidities- $n(\%)$} \\
\hline Smoking & $5(5.26)$ & $5(6.58)$ & $0(0.00)$ & N/A \\
\hline Hypertension & $26(27.37)$ & $22(28.95)$ & $4(21.05)$ & 0.490 \\
\hline Diabetes & $10(10.53)$ & $9(11.84)$ & $1(5.26)$ & 0.403 \\
\hline Cardiovascular disease & $7(7.37)$ & $5(6.58)$ & $2(10.53)$ & 0.556 \\
\hline Cerebrovascular disease & $3(3.16)$ & $3(3.95)$ & $0(0.00)$ & N/A \\
\hline Chronic pulmonary disease & $5(5.26)$ & $5(6.58)$ & $0(0.00)$ & N/A \\
\hline Chronic kidney disease & $0(0.00)$ & $0(0.00)$ & $0(0.00)$ & N/A \\
\hline Chronic liver disease & $6(6.32)$ & $5(6.58)$ & $1(5.26)$ & 0.833 \\
\hline Rheumatic immune disease & $0(0.00)$ & $0(0.00)$ & $0(0.00)$ & N/A \\
\hline Malignancies & $2(2.11)$ & $2(2.63)$ & $0(0.00)$ & N/A \\
\hline \multicolumn{5}{|l|}{ Clinical symptoms- $n(\%)$} \\
\hline Fever & 85 (89.47) & $66(86.84)$ & $19(100)$ & 0.095 \\
\hline Cough & $57(60.00)$ & $54(71.05)$ & $3(15.79)$ & 0.000 \\
\hline Expectoration & $28(29.47)$ & $24(31.58)$ & $4(21.05)$ & 0.368 \\
\hline Dyspnea & $33(34.74)$ & $25(32.89)$ & $8(42.11)$ & 0.451 \\
\hline Pharyngalgia & $2(2.11)$ & $1(1.32)$ & $1(5.26)$ & 0.284 \\
\hline Dizziness & $2(2.11)$ & $2(2.63)$ & $0(0.00)$ & N/A \\
\hline Myalgia & $1(1.05)$ & $1(1.32)$ & $0(0.00)$ & N/A \\
\hline Fatigue & $22(23.16)$ & $18(23.68)$ & $4(21.05)$ & 0.808 \\
\hline Nausea or vomiting & $4(4.21)$ & $4(5.26)$ & $0(0.00)$ & N/A \\
\hline Diarrhea & $5(5.26)$ & $5(6.58)$ & $0(0.00)$ & N/A \\
\hline $\mathrm{SpO} 2(\leqslant 93 \%)$ & $17(17.89)$ & 15 (19.74) & $2(10.53)$ & 0.349 \\
\hline $\mathrm{HR}(>100)$ & $19(20.00)$ & $14(18.42)$ & $5(26.32)$ & 0.442 \\
\hline Duration of positive time (IQR) & $28(20-45)$ & $24(19-34)$ & $54(49-57)$ & 0.000 \\
\hline
\end{tabular}

pressed as average, and quantitative data of non-normal distribution were calculated by quartile. The Chi-square test and Fisher exact test were used in the two groups of data, and the $t$-test or Mann-Whitney $\mathrm{U}$ test were used to analyze continuous variables. SPSS version 21.0 software was used for all statistical analyses. $P<0.05$ was considered statistically significant.

\section{Results}

\subsection{Clinical characteristics of the patients on admission}

Five hundred and sixty-eight cases of COVID-19 patients were diagnosed at the Xiaogan Central Hospital between 16 January 2020 and 28 March 2020. The demographic and clinical characteristics of the patients are summarized in Table 1. In particular, the median age was 52 years (IQR 43-63), and there were 306 males $(54.45 \%)$ and 256 females $(45.55 \%)$. The most common clinical symptoms were fever 


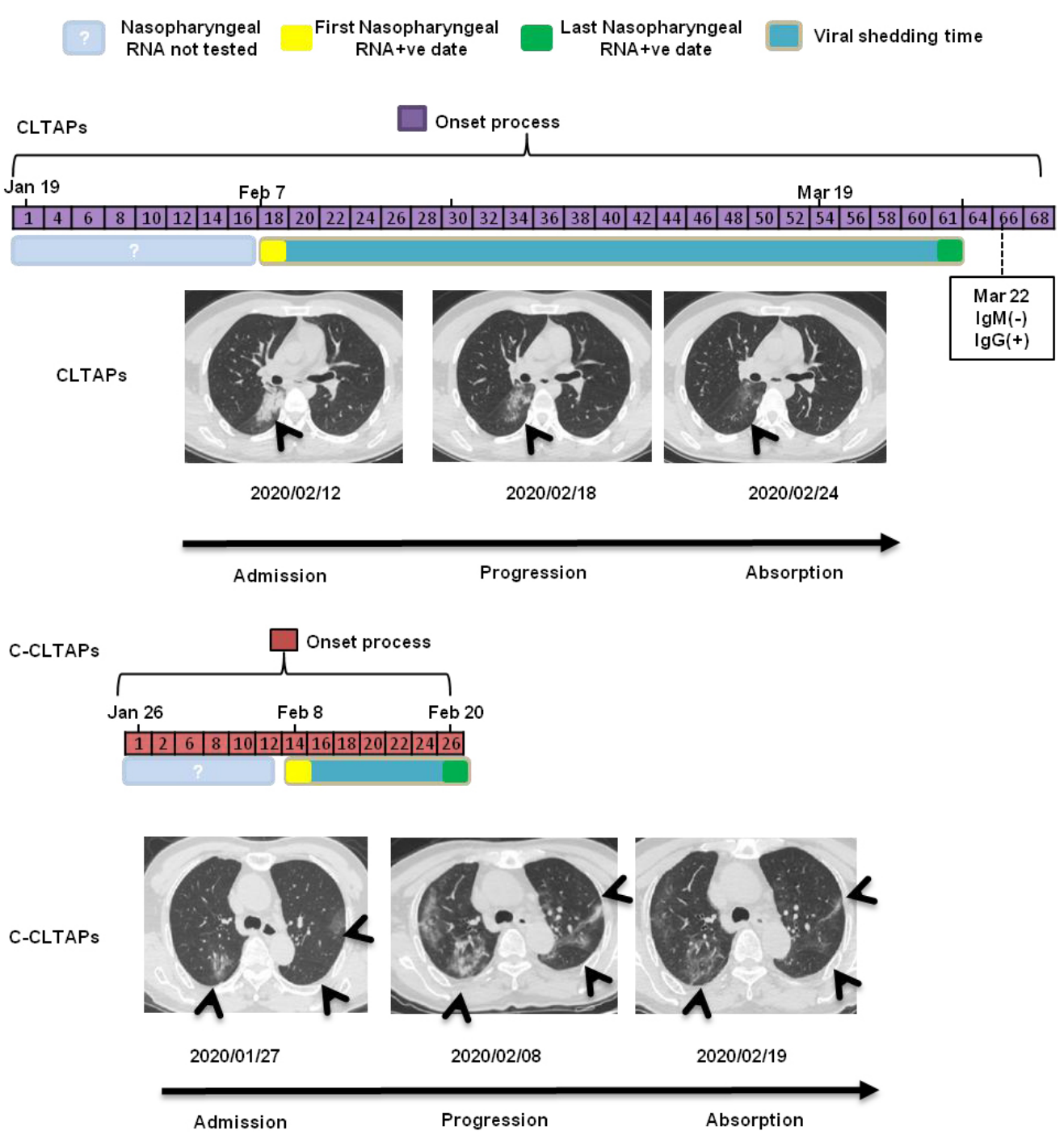

Fig. 1. Dynamic profile of C-CLTAPs and CLTAPs in CT characteristics and SARS-CoV-2 RNA test.

$(81.32 \%)$ and cough $(65.48 \%)$. Dyspnea (65.48\%), expectoration $(23.31 \%)$ and fatigue $(25.27 \%)$ were the next most common. Diarrhea $(4.27 \%)$, myalgia (5.34\%), dizziness $(1.42 \%)$, sore throat $(2.34 \%)$ and conjunctival congestion $(0.78 \%)$ were relatively uncommon. Most patients had a clear history of contact, including Wuhan travel history $(22.42 \%)$, Wuhan residential history $(10.50 \%)$ and contact history with diagnosed patients $(24.38 \%)$. The proportion of patients who denied a clear contact history was $42.70 \%$. Among these diagnosed patients, hypertension $(24.73 \%)$ was the most common chronic disease, followed by diabetes $(11.39 \%)$ and chronic liver disease $(6.58 \%)$. Disease stratification was 398 ordinary patients (70.81\%), 99 severe patients (17.61\%) and 65 critical patients $(11.56 \%)$.

\subsection{The distinction between CLTAPs and C-CLTAPs}

The median time of viral shedding in the 562 cases was 26 (18-36), which was similar to results of Zhou et al. [14]. However, we found that there were 19 patients with a median time of viral shedding of 
Table 3

Laboratory tests of C-CLTAPs and CLTAPs

\begin{tabular}{|c|c|c|c|c|}
\hline Laboratory findings & All patients $(n=95)$ & C-CLTAPs $(n=76)$ & CLTAPs $(n=19)$ & $p$ value \\
\hline \multicolumn{5}{|l|}{ Blood routine } \\
\hline White blood cell count $\left(\times 10^{9} / \mathrm{L}\right)$ & $5.17(4.21-7.15)$ & $5.24(4.14-7.32)$ & $4.80(4.40-6.41)$ & 0.638 \\
\hline Red blood cell count $\left(\times 10^{12} / \mathrm{L}\right)$ & $4.43(4.15-4.81)$ & $4.46(4.18-4.81)$ & $4.31(4.00-4.80)$ & 0.454 \\
\hline Hemoglobin & $139(127.50-149)$ & $140(128-149.75)$ & $133(123-145)$ & 0.293 \\
\hline Neutrophil $\left(\times 10^{9} / \mathrm{L}\right)$ & $3.49(2.56-5.12)$ & $3.54(2.56-5.81)$ & $3.39(2.61-4.07)$ & 0.424 \\
\hline Lymphocyte $\left(\times 10^{9} / \mathrm{L}\right)$ & $1.02(0.73-1.64)$ & $0.96(0.71-1.46)$ & $1.35(0.96-1.61)$ & 0.093 \\
\hline Platelet $\left(\times 10^{9} / \mathrm{L}\right)$ & $167(137-222.5)$ & $162.50(135-226.25)$ & $192(165-209)$ & 0.280 \\
\hline \multicolumn{5}{|l|}{ Blood coagulation } \\
\hline Active partial thrombin time (APTT) & $31.00(28.80-33.85)$ & $30.90(28.80-33.90)$ & $31.60(29.95-33.50)$ & 0.361 \\
\hline Prothrombin time $(\mathrm{PT})$ & $12.30(11.70-13.30)$ & $12.50(12.20-13.60)$ & $11.60(11.30-11.80)$ & 0.000 \\
\hline Fibrinogen (Fib) & $4.52(3.38-5.34)$ & $4.73(3.88-5.56)$ & $2.82(2.47-3.84)$ & 0.000 \\
\hline D-dimer (SDD) & $12.80(12.10-13.80)$ & $12.60(12.00-13.70)$ & $13.60(13.00-14.55)$ & 0.003 \\
\hline \multicolumn{5}{|l|}{ Biochemical routine } \\
\hline Total protein (TP) & $187.70(138.85-259.50)$ & $176.60(128.83-222.68)$ & 264 (209.95-295.30) & 0.002 \\
\hline Albumin propagated (ALB) & $68.70(64.80-73.80)$ & $66.85(63.78-70.65)$ & $79.70(72.30-86.45)$ & 0.000 \\
\hline Alanine aminotransferase (ALT) & $38.20(35.65-40.75)$ & $38.05(35.13-40.10)$ & $40.90(38.15-43.05)$ & 0.002 \\
\hline Glutamates transaminase (AST) & $18(11-31)$ & $20.00(12.00-33.25)$ & $14(8-22.50)$ & 0.059 \\
\hline Total bilirubin & $23(16.50-30)$ & $23.50(17.00-31.50)$ & $20(15-26)$ & 0.164 \\
\hline Urea nitrogen & $11.40(9.50-16.75)$ & $11.95(9.50-16.53)$ & $11.20(9.20-16.15)$ & 0.539 \\
\hline Creatinine & $4.70(3.35-5.80)$ & $4.50(3.30-5.63)$ & $5.40(4.10-5.80)$ & 0.340 \\
\hline eGFR & $73.30(60.45-88)$ & $70.70(59.23-83.30)$ & $88(72.75-91.50)$ & 0.066 \\
\hline Lactate dehydrogenase (LDH) & $69(47-106.25)$ & $64.50(45.00-107.75)$ & $72.00(60.75-90.50)$ & 0.364 \\
\hline Alkaline phosphatase (ALP) & $72(65-85)$ & $69(63.50-82.25)$ & $86(77-106.50)$ & 0.005 \\
\hline Fasting plasma glucose (FPG) & $5.54(5.05-6.46)$ & $5.59(5.18-6.91)$ & $5.01(4.28-5.38)$ & 0.002 \\
\hline Total cholesterol (TC) & $3.60(3.08-4.19)$ & $3.50(2.96-4.07)$ & $4.23(3.63-4.58)$ & 0.005 \\
\hline Triglyceride (TG) & $1.35(1.03-1.96)$ & $1.28(1.00-1.84)$ & $1.46(1.17-2.63)$ & 0.023 \\
\hline \multicolumn{5}{|l|}{ Four items of chest pain } \\
\hline Creatinase isoenzyme (CKMB) & $2.06(1.47-3.01)$ & $2.10(1.51-2.88)$ & $1.50(1.38-4.71)$ & 0.911 \\
\hline $\begin{array}{l}\text { N-terminal brain natriuretic peptide } \\
\text { precursor (BNP) }\end{array}$ & $157(51-404)$ & $156.50(66-408)$ & $214(20-376)$ & 0.649 \\
\hline Myoglobin (Myo) & $53.29(40.14-113.60)$ & 52.95 (40.79-122.23) & $64.76(30.98-71.56)$ & 0.596 \\
\hline Cardiac troponin (cTnI) & $0.06(0.03-0.09)$ & $0.06(0.04-0.09)$ & $0.04(0.02-0.06)$ & 0.094 \\
\hline \multicolumn{5}{|l|}{ Infection-related index } \\
\hline PCT & $0.18(0.13-0.27)$ & $0.16(0.12-0.27)$ & $0.20(0.18-0.23)$ & 0.053 \\
\hline CRP & $8.17(2.90-32.05)$ & $13.20(3.70-37.51)$ & $2.30(1.11-3.52)$ & 0.001 \\
\hline ESR & $47(31-68.25)$ & $47(32-69)$ & $19(18-55)$ & 0.100 \\
\hline
\end{tabular}

54 (IQR 49-57), which were considered as CLTAPs. To further explore the characteristics of these 19 CLTAPs, we matched 76 cases of C-CLTAPs of the same gender and age according to a 1:4 ratio, and compared the demographic characteristics, clinical symptoms, laboratory tests, and imaging data between the two groups.

Demographic and clinical characteristics of the CLTAPs and C-CLTAPs are summarized in Table 2. In detail, among the 95 COVID-19 patients, the median age was 57 years (IQR 48-60), and there were 75 males $(78.95 \%)$ and 20 females $(21.05 \%)$. There was no significant difference between CLTAPs and C-CLTAPs in exposure history and comorbidities. In terms of clinical symptoms, the symptoms of CLTAPs were milder than those of C-CLTAPs, and the proportion of CLTAPs with cough symptoms was significantly lower than that of C-CLTAPs $(15.79 \%$ vs $71.05, P<0.05)$. In addition, the median duration of viral shedding of CLTAPs was significantly shorter than that of the C-CLTAPs (54 IQR [49-57] vs 24 IQR [19-34], $P<0.05$ ) (Fig. 1). These results suggest that in comparison to C-CLTAPs, CLTAPs had milder clinical symptoms and longer viral shedding time. 
Table 4

Treatment and clinic outcomes of C-CLTAPs and CLTAPs

\begin{tabular}{|c|c|c|c|c|}
\hline & $\begin{array}{l}\text { All patients } \\
(n=95)\end{array}$ & $\begin{array}{c}\text { C-CLTAPs } \\
(n=76)\end{array}$ & $\begin{array}{l}\text { CLTAPs } \\
(n=19)\end{array}$ & $p$ value \\
\hline \multicolumn{5}{|l|}{ Oxygen cure- $n(\%)$} \\
\hline Oxygen- $n$ & $31(32.63)$ & $28(36.84)$ & $3(15.79)$ & 0.080 \\
\hline \multicolumn{5}{|l|}{ Respiratory support- $n(\%)$} \\
\hline Non-invasive ventilator & $5(5.26)$ & $5(6.58)$ & $0(0.00)$ & N/A \\
\hline Invasive ventilator & $2(2.11)$ & $2(2.63)$ & $0(0.00)$ & N/A \\
\hline \multicolumn{5}{|l|}{ Drug treatment- $n(\%)$} \\
\hline \multicolumn{5}{|l|}{ Antiviral therapy } \\
\hline Abidor & $40(42.11)$ & $24(31.58)$ & $16(84.21)$ & 0.000 \\
\hline Interferon & $44(46.32)$ & $26(34.21)$ & $18(94.74)$ & 0.000 \\
\hline Ganciclovir & $24(25.26)$ & $22(28.95)$ & $2(10.53)$ & 0.098 \\
\hline Oseltamivir & $35(36.84)$ & $33(43.42)$ & $2(10.53)$ & 0.008 \\
\hline Pironavir ritonavir & $30(31.58)$ & $19(25.00)$ & $11(57.89)$ & 0.006 \\
\hline Ribavirin & $37(38.95)$ & $32(42.11)$ & $5(26.32)$ & 0.207 \\
\hline Hydroxychloroquine & $19(20.00)$ & $6(7.89)$ & $13(68.42)$ & 0.000 \\
\hline \multicolumn{5}{|l|}{ Antibiotic treatment } \\
\hline Moxifloxacin & $48(50.53)$ & $43(56.58)$ & $5(26.32)$ & 0.018 \\
\hline Levofloxacin & 15 (15.79) & $14(18.42)$ & $1(5.26)$ & 0.159 \\
\hline Piperacillin tazobactam & $3(3.16)$ & $3(3.95)$ & $0(0.00)$ & N/A \\
\hline Cefoperazone sodium sulbactam sodium & $1(1.05)$ & $1(1.32)$ & $0(0.00)$ & N/A \\
\hline Glucocorticoid & $1(1.05)$ & $1(1.32)$ & $0(0.00)$ & N/A \\
\hline Gamma globulin & $37(38.95)$ & $35(46.05)$ & $2(10.53)$ & 0.005 \\
\hline \multicolumn{5}{|l|}{ Complications- $n(\%)$} \\
\hline Septicemia & $0(0.00)$ & $0(0.00)$ & $0(0.00)$ & N/A \\
\hline Respiratory failure & $13(13.68)$ & $13(17.11)$ & $0(0.00)$ & N/A \\
\hline ARDS & $1(1.05)$ & $1(1.32)$ & $0(0.00)$ & N/A \\
\hline Heart failure & $2(2.11)$ & $2(2.63)$ & $0(0.00)$ & N/A \\
\hline Septic shock & $0(0.00)$ & $0(0.00)$ & $0(0.00)$ & N/A \\
\hline Coagulopathy & $0(0.00)$ & $0(0.00)$ & $0(0.00)$ & N/A \\
\hline Acute kidney injury & $1(1.05)$ & $1(1.32)$ & $0(0.00)$ & N/A \\
\hline Acute heart injury & $1(1.05)$ & $1(1.32)$ & $0(0.00)$ & N/A \\
\hline \multicolumn{5}{|l|}{ Clinical classification } \\
\hline Ordinary & $71(74.74)$ & $54(71.05)$ & 17 (89.47) & 0.098 \\
\hline Severe & $16(16.84)$ & $14(18.42)$ & $2(10.53)$ & 0.411 \\
\hline Critically ill & $8(8.42)$ & $8(10.53)$ & $0(0.00)$ & N/A \\
\hline \multicolumn{5}{|l|}{ Clinical outcome- $n(\%)$} \\
\hline Discharge & $91(95.79)$ & $72(94.74)$ & $19(100.00)$ & 0.307 \\
\hline Death & $4(4.21)$ & $4(5.26)$ & $0(0.00)$ & 0.307 \\
\hline
\end{tabular}

Laboratory tests of the CLTAPs and C-CLTAPs are summarized in Table 3. In comparison to CCLTAPs, white and red blood cells, hemoglobin and neutrophils of CLTAPs decreased and lymphocyte and platelet increased. These results suggest that CLTAPs were more likely to have a lower proportion of inflammatory markers at admission. This was consistent with the result that CLTAPs had a lower infection index in comparison to C-CLTAPs at admission.

Treatment and clinic outcomes of the CLTAPs and C-CLTAPs are summarized in Table 4. In detail, CLTAPs showed no clinical complications, while C-CLTAPs contained mild clinical complications, including 13 cases of respiratory failure, 1 case of ARDS and 2 cases of heart failure. CLTAPs used less oxygen therapy and had a higher proportion of hydroxychloroquine treatment in comparison to C-CLTAPs. In terms of clinical classification, CLTAPs held more mild patients, which was also the reason for the low proportion of glucocorticoids and globulin use.

Radiological data of the CLTAPs and C-CLTAPs are summarized in Table 5. Specifically, according 
Table 5

Radiological data of C-CLTAPs and CLTAPs

\begin{tabular}{|c|c|c|c|c|}
\hline & $\begin{array}{l}\text { All patients } \\
(n=95)\end{array}$ & $\begin{array}{l}\text { C-CLTAPs } \\
(n=76)\end{array}$ & $\begin{array}{l}\text { CLTAPs } \\
(n=19)\end{array}$ & $p$ value \\
\hline \multicolumn{5}{|l|}{ Lesion distribution- $n(\%)$} \\
\hline Left lung & $5(5.26)$ & $5(6.58)$ & $0(0.00)$ & N/A \\
\hline Right lung & $7(7.37)$ & $7(9.21)$ & $0(0.00)$ & N/A \\
\hline Double lung & $65(68.42)$ & $58(76.32)$ & $7(36.84)$ & 0.001 \\
\hline \multicolumn{5}{|l|}{ Lesion location- $n(\%)$} \\
\hline Periphery & $41(43.16)$ & $37(48.68)$ & $4(21.05)$ & 0.030 \\
\hline Periphery and center & $36(37.89)$ & $33(43.42)$ & $3(15.79)$ & 0.026 \\
\hline \multicolumn{5}{|l|}{ Lesion size $(\mathrm{cm})-n(\%)$} \\
\hline$<1$ & $5(5.26)$ & $5(6.58)$ & $0(0.00)$ & N/A \\
\hline $1 \sim 3$ & $11(11.58)$ & $7(9.21)$ & $4(21.05)$ & 0.149 \\
\hline$>3$ & $61(64.21)$ & $58(76.32)$ & $3(15.79)$ & 0.000 \\
\hline \multicolumn{5}{|l|}{ Lesions form- $n(\%)$} \\
\hline Patch & $40(42.11)$ & $36(47.37)$ & $4(21.05)$ & 0.038 \\
\hline Lung segment & $20(21.05)$ & $18(23.68)$ & $2(10.53)$ & 0.208 \\
\hline Lobe & $17(17.89)$ & $16(21.05)$ & $1(5.26)$ & 0.108 \\
\hline \multicolumn{5}{|l|}{ Number of lesions- $n(\%)$} \\
\hline 1 & $6(6.32)$ & $6(7.89)$ & $0(0.00)$ & N/A \\
\hline 2 & $9(9.47)$ & $6(7.89)$ & $3(15.79)$ & 0.293 \\
\hline 3 or more & $62(65.26)$ & $58(76.32)$ & $4(21.05)$ & 0.000 \\
\hline \multicolumn{5}{|l|}{ Lesion margin- $n(\%)$} \\
\hline Clear & $4(4.21)$ & $4(5.26)$ & $0(0.00)$ & N/A \\
\hline Vague & $73(76.84)$ & $66(86.84)$ & $7(36.84)$ & 0.000 \\
\hline \multicolumn{5}{|l|}{ Lesion density- $n(\%)$} \\
\hline Ground glass & $42(44.21)$ & 37 (48.68) & $5(26.32)$ & 0.079 \\
\hline Substantiality & $1(1.05)$ & $1(1.32)$ & $0(0.00)$ & N/A \\
\hline Mixed type & $35(36.84)$ & $33(43.42)$ & $2(10.53)$ & 0.008 \\
\hline \multicolumn{5}{|l|}{ Extrapulmary manifestations- $n(\%)$} \\
\hline Mediastinal lymphadenopathy & $0(0.00)$ & $0(0.00)$ & $0(0.00)$ & N/A \\
\hline Pneumothorax & $0(0.00)$ & $0(0.00)$ & $0(0.00)$ & N/A \\
\hline Pleural effusion & $4(4.21)$ & $4(5.26)$ & $0(0.00)$ & N/A \\
\hline
\end{tabular}

to the distribution characteristics and the range of involvement of COVID-19 lung CTs, we counted the imaging characteristics of lung CTs in the first week of admission. Among all patients, the proportion of lesions involving both lungs was $68.42 \%$, the proportion of lesion distribution simultaneously involving peripheral and central areas was $37.89 \%$, the proportion of the lesion size of $>3 \mathrm{~cm}$ was $64.21 \%$, the proportion of 3 or more lesions was $65.26 \%$, and the proportion of the lesion edge vague was $76.84 \%$. In terms of lung CT lesion involvement location, compared with C-CLTAPs, the proportion of peripheral and central involvement of the CLTAPs was significantly lower (43.42\% vs $15.79 \%, P<0.05)$. The proportion of the lesion size of $>3 \mathrm{~cm}$ of C-CLTAPs was significantly higher than CLTAPs (76.32\% vs $15.79 \%, P<0.05$ ). More importantly, we found that C-CLTAPs in the pulmonary CT progression group were much faster than CLTAPs, while the time of pulmonary CT absorption of C-CLTAPs was a lot longer than in the CLTAPs group (Fig. 1). These results indicate that in comparison to C-CLTAPs, CLTAPs showed slower pulmonary CT progression and faster pulmonary CT absorption.

\section{Discussion}

Scientists have made efforts to reveal the epidemiological, clinical and virological characteristics of SARS-CoV-2 [15-20]. COVID-19 infection has some similarities with SARS-CoV and MERS-CoV 
infection [21,22], but it has obviously strong transmissibility. We are concerned that 2019-nCoV may have acquired efficient human transportation capabilities [23]. In the present study, we reported a cohort of 562 patients with laboratory-confirmed COVID-19 infection. Patients' personal, clinical, laboratory, radiologic characteristics, epidemiological, treatment, and outcome information was analyzed. The disease stratification was 398 ordinary patients $(70.81 \%), 99$ severe patients $(17.61 \%)$ and 65 critical patients $(11.56 \%)$.

In addition, we compared 19 cases of CLTAPs with 76 cases of C-CLTAPs in terms of clinical characteristics, treatment, clinic outcomes and CT characteristics. Compared with C-CLTAPs, CLTAPs had a lower infection index at admission (CRP: 13.20 IQR [3.70-37.51] vs 2.30 IQR [1.11-3.52], $P<0.001$ ). The milder clinical symptoms (proportion of cough symptoms: CLTAPs [15.79\%] vs CCLTAPs [71.05\%], $P<0.05$ ) and a lower proportion of inflammatory markers of CLTAPs at admission, which indicates that immunity played an important role in the recovery of COVID-19 and the viral shedding time. The median duration of viral shedding of CLTAPs was significantly shorter than that of C-CLTAPs (54 IQR [49-57] vs 24 IQR [19-34], $P<0.05$ ). 17 of the 19 cases tested positive for COVID-19 IgG on March 22 2020. This indicates that although CLTAPs had a lower immune response due to mild clinical symptoms in the early stage of the COVID-19 infection, the immune response of CLTAPs was still activated in the later stage of the disease. This suggests that the COVID-19 shedding time had a relationship with host immunity, which was consistent with the CT results of the CLTAPs, which showed slower pulmonary CT progression and faster pulmonary CT absorption in comparison to C-CLTAPs.

\section{Conclusion}

In conclusion, we analyzed and discussed the clinical features of 562 cases of COVID-19 patients. We compared and analyzed the clinical differences between CLTAPs and C-CLTAPs, providing a theoretical basis for the treatment of C-CLTAPs and the next stage of prevention and control work.

\section{Author contributions}

Y. Yan and M. Wang conceived and designed the study. X. Zhu and F. Yang acquired the data. Q. Li and T. Zhao performed the analysis. Y. Yan wrote the manuscript. W. Li reviewed and edited the manuscript. All authors read and approved the final manuscript and agree to be accountable for all aspects of the research in ensuring that the accuracy or integrity of any part of the work are appropriately investigated and resolved.

\section{Conflict of interest}

None of the authors have any conflict of interest to report.

\section{Informed consent}

All patients provided informed consent for the publication of this study. 


\section{References}

[1] Richman DD, Whitley RJ, Hayden FG, eds. Clinical virology, $4^{\text {th }}$ edn. Washington: ASM Press; 2016.

[2] Weiss SR, Leibowitz JL. Coronavirus pathogenesis. Adv Virus Res. 2011; 81: 85-164.

[3] Masters PS, Perlman S. Coronaviridae. In: Knipe DM, Howley PM, eds. Fields virology. 6th ed. Lippincott Williams \& Wilkins, 2013: pp. 825-58.

[4] Su S, Wong G, Shi W, et al. Epidemiology, genetic recombination, and pathogenesis of coronaviruses. Trends Microbiol. 2016; 24: 490-502.

[5] Bender SJ, Phillips JM, Scott EP, Weiss SR. Murine coronavirus receptors are differentially expressed in the central nervous system and play virus strain-depen- dent roles in neuronal spread. J. Virol. 2010; 84: 11030-11044.

[6] Bergmann CC, Lane TE, Stohlman SA. Coronavirus infection of the central nervous system: host-virus stand-off. Nat. Rev. Microbiol. 2006; 4: 121-132.

[7] Su S, Wong G, Shi W, et al. Epidemiology, genetic recombination, and pathogenesis of coronaviruses. Trends Microbiol. 2016; 24: 490-502.

[8] Cui J, Li F, Shi ZL. Origin and evolution of pathogenic coronaviruses. Nat Rev Microbiol. 2019; 17: 181-92.

[9] Zhu N, Zhang D, et al. A novel coronavirus from patients with pneumonia in China, 2019. NEnglJ Med. 2020; 382: 727-33. doi: 10.1056/NEJMoa2001017.

[10] Huang C, Wang Y, et al. Clinical features of patients infected with 2019 novel coronavirus in Wuhan, China. Lancet. 2020; 395: 497-506.

[11] Cui J, Li F, Shi ZL. Origin and evolution of pathogenic coronaviruses. Nat Rev Microbiol. 2019; 17: 181-92.

[12] Wong G, Liu W, Liu Y, Zhou B, Bi Y, Gao GF. MERS, SARS, and Ebola: the role of super-spreaders in infectious disease. Cell Host Microbe. 2015; 18: 398-401.

[13] Lai CC, Shih TP, Ko WC, et al. Severe acute respiratory syndrome coronavirus 2 (SARS-CoV-2) and coronavirus disease-2019 (COVID-19): the epidemic and the challenges. Int J Antimicrob Agents. 2020 Mar; 55(3).

[14] Zhou F, Yu T, Du R, et al. Clinical course and risk factors for mortality of adult inpatients with COVID-19 in Wuhan, China: a retrospective cohort study. Lancet. 202003 28; 395(10229).

[15] Zhao S, Lin Q, Ran J, et al. Preliminary estimation of the basic reproduction number of novel coronavirus (2019- ncoV) in china, from 2019 to 2020: a data- driven analysis in the early phase of the outbreak. Int J Infect Dis. 2020; 92: 214-7.

[16] Bogoch ii, Watts a, Thomas-Bachli a, et al. Potential for global spread of a novel coronavirus from china. J Travel Med. 2020; 27.

[17] Chen N, Zhou M, Dong X, et al. epidemiological and clinical characteristics of 99 cases of 2019 novel coronavirus pneumonia in Wuhan, China: a descriptive study. Lancet. 2020; 395: 507-13.

[18] Huang C, Wang Y, Li X, et al. Clinical features of patients infected with 2019 novel coronavirus in Wuhan, China. Lancet. 2020; 395: 497-506.

[19] Li Q, Guan X, Wu P, et al. Early transmission dynamics in Wuhan, china, of novel coronavirus-infected pneumonia. N Engl J Med. 2020. doi: 10.1056/neJMoa2001316. [epub ahead of print: 29 Jan 2020].

[20] Wu JT, Leung K, Leung GM. nowcasting and forecasting the potential domestic and international spread of the 2019ncoV outbreak originating in Wuhan, china: a modelling study. Lancet. 2020; 395: 689-97.

[21] Lee N, Hui D, Wu A, et al. A major outbreak of severe acute respiratory syndrome in Hong Kong. N Engl J Med. 2003; 348: 1986-94.

[22] Assiri A, Al-Tawfiq JA, Al-Rabeeah AA, et al. Epidemiological, demographic, and clinical characteristics of 47 cases of Middle East respiratory syndrome coronavirus disease from Saudi Arabia: a descriptive study. Lancet Infect Dis. 2013; 13: 752-61.

[23] Perlman S, Netland J. Coronaviruses post-SARS: update on replication and pathogenesis. Nat Rev Microbiol. 2009; 7 : 439-50. 